\title{
Aeromonas Isolates from Human Diarrheic Stool and Groundwater Compared by Pulsed-Field Gel Electrophoresis
}

\author{
Mark A. Borchardt, ${ }^{*}$ Mary E. Stemper, $\dagger$ and Jon H. Standridge‡
}

\begin{abstract}
Gastrointestinal infections of Aeromonas species are generally considered waterborne; for this reason, Aeromonas hydrophila has been placed on the United States Environmental Protection Agency Contaminant Candidate List of emerging pathogens in drinking water. In this study, we compared pulsedfield gel electrophoresis patterns of Aeromonas isolates from stool specimens of patients with diarrhea with Aeromonas isolates from patients' drinking water. Among 2,565 diarrheic stool specimens submitted to a Wisconsin clinical reference laboratory, $17(0.66 \%)$ tested positive for Aeromonas. Groundwater isolates of Aeromonas were obtained from private wells throughout Wisconsin and the drinking water of Aeromonaspositive patients. The analysis showed that the stool and drinking water isolates were genetically unrelated, suggesting that in this population Aeromonas gastrointestinal infections were not linked with groundwater exposures.
\end{abstract}

$\mathbf{T}$ he Safe Drinking Water Act amendment of 1996 requires the United States Environmental Protection Agency (EPA) to establish a list of contaminants of public health concern that are known or anticipated to occur in drinking water systems and may require future regulation under the Safe Drinking Water Act. The list, known as the Contaminant Candidate List, is intended to generate scientific research that will assist the EPA in creating new regulations to protect the public from health risks associated with drinking water. Currently, the putatively emerging enteric pathogen, Aeromonas hydrophila, is included in the list because it has the potential to grow in water distribution systems, especially in biofilms, where it may be resistant to chlorination (1). However, the role of drinking water consumption in Aeromonas infections is unclear.

Three phenotypically defined species, A. hydrophila, A. caviae, and $A$. veronii biotype sobria, constitute $85 \%$ of all clinical isolates involved with gastrointestinal and extraintestinal infections (2). Whether Aeromonas is indeed a causative agent of gastroenteritis has been debated. Numerous case

*Marshfield Medical Research Foundation, Marshfield, Wisconsin, USA; †Marshfield Laboratories, Marshfield, Wisconsin, USA; and ¥University of Wisconsin, State Laboratory of Hygiene, Madison, Wisconsin, USA reports have described isolating Aeromonas from patients with acute diarrhea, but the bacterium can also be isolated from stool of healthy persons (3). Determining the enteropathogenicity of Aeromonas has been inconclusive, probably because of differences in diarrheagenic potential among strains. A consensus appears to be growing that certain strains are likely human enteric pathogens $(2,4)$.

Aeromonas is ubiquitous in water, including chlorinated drinking water (5-7). In surface water, Aeromonas abundance peaks in the warm summer and fall months $(8,9)$. In one municipality, the seasonal increase in Aeromonas detection in the drinking water supply matched the peak occurrence of clinical isolates (8). Aeromonas also occurs in groundwater $(6,10,11)$, and in a single well, the same strain can persist for years (11). Some strains of Aeromonas isolated from water have been shown to possess virulence traits, such as adhesions, hemolysins, and cytotonic enterotoxins, presumably involved with human pathogenicity $(3,12,13)$.

If Aeromonas enteric infections are transmitted by drinking water and symptomatic infections are strain-specific, then the same strains isolated from patients with acute gastroenteritis should be found in drinking water. The objective of this study was to isolate Aeromonas from patients with acute diarrhea and, by using pulsed-field gel electrophoresis (PFGE), compare the molecular fingerprints of these isolates with isolates from the patients' drinking water.

\section{Methods}

\section{Fecal Specimens}

This study was reviewed and approved by the Institutional Review Board of Marshfield Clinic. All diarrheic stool specimens submitted by physicians to Marshfield Laboratories, a clinical reference laboratory, for routine microbiologic analysis were screened for Aeromonas during two periods, July 28November 13, 1998, and June 2-October 18, 1999. Specimens were plated for Aeromonas within 2-3 days after submission. Stool in Cary-Blair transport media was directly streaked to sheep blood agar containing $10 \mu \mathrm{g} / \mathrm{mL}$ ampicillin (14) (Remel, Lenexa, KS) and incubated at $35^{\circ} \mathrm{C}$. Presumptive Aeromonas isolates were screened for standard phenotypic traits $(\beta$ hemolysis, oxidase positive, indole positive), and species iden- 
tity was determined by using the API-20E identification system (10th edition, analytical profile index, bioMérieux, Marcy-'Etoile, France).

\section{Drinking Water Samples}

Patients with positive results for Aeromonas were asked to allow a trained technician to collect a water sample from their residence. Samples were collected within 1-3 weeks after the clinical isolate was identified. Aeromonas was directly cultured from two $100-\mathrm{mL}$ water samples by using ampicillin dextrin agar in a membrane filtration technique (15). One sample was incubated at $30^{\circ} \mathrm{C}$ and the other at $35^{\circ} \mathrm{C}$. Yellow oxidase-positive colonies were streaked for purity and confirmed as Aeromonas by using the API-20E (bioMérieux) identification system. Stool and water isolates were stored in Microbank cryovials (Pro-Lab Diagnostics, Richmond Hill, Ontario, Canada) at $-70^{\circ} \mathrm{C}$ for subsequent PFGE.

\section{PFGE}

The PFGE procedure for Aeromonas was modified from methods previously described $(16,17)$. Isolates were grown overnight in $5 \mathrm{~mL}$ of brain heart infusion broth at $37^{\circ} \mathrm{C}$, harvested by centrifugation, and washed with $1 \mathrm{~mL}$ resuspension buffer (10 mM Tris-HCl [pH 7.6], $1 \mathrm{M} \mathrm{NaCl}$ ). Pelleted cells were adjusted to a concentration of $1 \times 10^{9} \mathrm{CFU} / \mathrm{mL}$ in resuspension buffer by using a Vitek colorimeter (Hach Co., Loveland, $\mathrm{CO}$ ), mixed with an equal volume of $2 \%$ low melt agarose (FMC BioProducts, Rockland, ME), dispensed into plug molds (Bio-Rad Laboratories, Hercules, CA), and allowed to solidify $10 \mathrm{~min}$ at room temperature. Plugs were incubated in $3 \mathrm{~mL}$ lysis buffer ( $6 \mathrm{mM}$ Tris-Cl, $1.0 \mathrm{M} \mathrm{NaCl}, 0.1$ M EDTA, $0.5 \%$ Brij 58, 0.5\% sarkosyl, $0.2 \%$ deoxycholate, 1 $\mathrm{mg} / \mathrm{mL}$ lysozyme) at $37^{\circ} \mathrm{C}$ for $4 \mathrm{~h}$. Lysis buffer was replaced with proteinase $\mathrm{K}$ solution $(0.5 \mathrm{M}$ EDTA, $1 \%$ N-lauroyl sarcosine, $1 \mathrm{mg} / \mathrm{mL}$ proteinase $\mathrm{K}$ ) followed by incubation at $55^{\circ} \mathrm{C}$ overnight. Plugs were washed 3 times in Tris-EDTA buffer (10 $\mathrm{mM}$ Tris- $\mathrm{HCl}, 0.1 \mathrm{M}$ EDTA [pH 8.0]) and stored at $4{ }^{\circ} \mathrm{C}$. Genomic DNA was digested with $30 \mathrm{U} X b a \mathrm{I}$ (Promega Corp., Madison, WI) at $37^{\circ} \mathrm{C}$ overnight. Electrophoresis was performed in $1 \%$ Seakem agarose (FMC Bioproducts) by using the CHEF-DRIII system (Bio-Rad Laboratories) in 0.5 $\times$ TBE buffer ( $45 \mathrm{mM}$ Tris, $45 \mathrm{mM}$ boric acid, $1 \mathrm{mM}$ EDTA [pH 8.0]) at $14^{\circ} \mathrm{C}$. The running parameters were $150 \mathrm{~V}$ for $12 \mathrm{~h}$ with 20 sec pulses and $17 \mathrm{~h}$ with 5 - to 15 -sec pulse times. One $A$. hydrophila isolate (isolate 1320) was run in multiple lanes of each gel as a DNA global reference for standardizing runs. DNA band size was determined from Staphylococcus aureus strain NCTC 8325 DNA, digested with SmaI. DNA banding patterns were visualized with $0.1 \%$ ethidium bromide and digitally photographed. Molecular Analyst Fingerprinting Plus software (version 1.12, Bio-Rad Laboratories) was used to compare the genetic similarity among isolates and construct a similarity dendrogram by using the Dice coefficient and the UPGMA algorithm (unweighted pair-group method with arithmetic mean) with a position tolerance of $1.5 \%$.

\section{Results}

Cultures for Aeromonas were performed on 2,565 diarrheic stool specimens from 2,310 patients. The median age of the patient population was 37 years (range 4 days to 97 years), and 55\% were female. Most specimens (97.6\%) were from patients residing in Wisconsin, primarily the central portion of the state, where groundwater, either from a municipal system or private well, is the source of drinking water (Figure 1). Some specimens came from communities along Lake Michigan where lake water is the source of drinking water.

Seventeen specimens $(0.66 \%)$ from 17 patients $(0.74 \%)$ tested positive for Aeromonas. Three stool isolates were identified as $A$. hydrophila and 14 isolates were $A$. caviae. All positive specimens were from Wisconsin residents. The median age of Aeromonas-positive patients was 27 years (range 1 month to 87 years) and 59\% were male. Five Aeromonas-positive patients were coinfected with one other enteric pathogen (two patients with Campylobacter, one with Salmonella, one with Cryptosporidium, and one with Clostridium difficile toxin A), suggesting that in these patients Aeromonas may have been a transient colonizer.

Fourteen of the Aeromonas-positive patients agreed to have their drinking water sampled. Five patients resided in a household with a private well, eight were served by municipal wells, and one lived in a municipality that used Lake Michigan for its drinking water. Except for one system, all municipal water was chlorinated. One drinking water source, a private well, tested positive for A. hydrophila. Designing this study, we assumed that the fecal carriage rate of Aeromonas would be

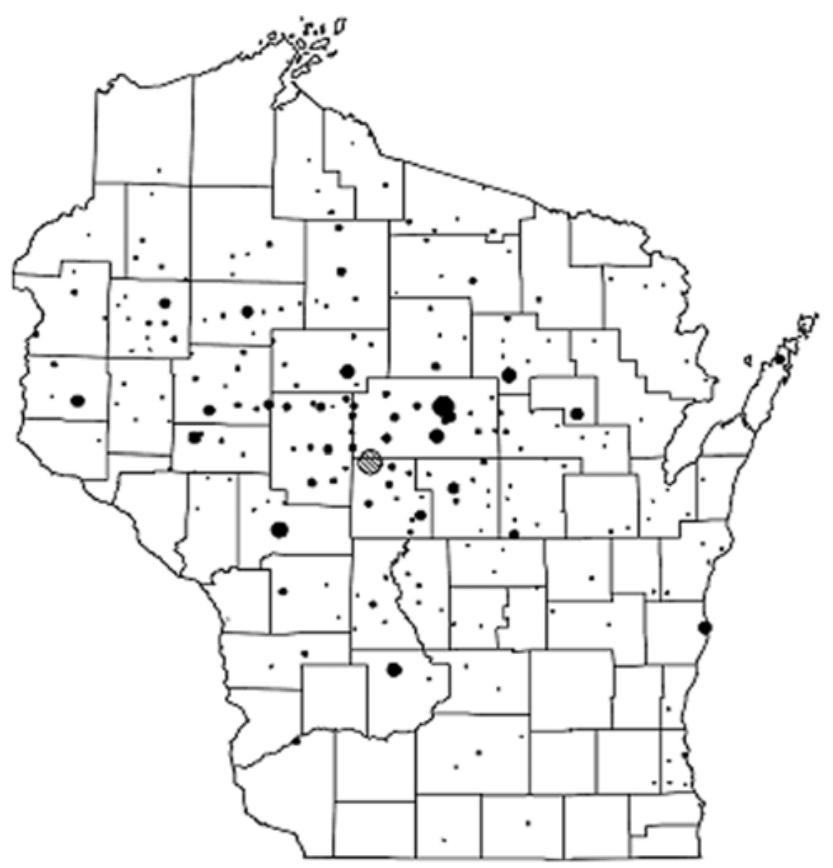

Figure 1. Location of Wisconsin residents who submitted diarrheic stool specimens to Marshfield Laboratories. The symbol indicates the location of Marshfield, WI. Symbol size is proportional to the number of specimens. (For reference, the symbol for Marshfield $=208$ specimens.) 
similar to its carriage rate in another study conducted in the Midwest (18) and, based on the ubiquitous occurrence of Aeromonas in water, we anticipated that a number of isolates would be collected from patients' drinking water. Since only one was collected, additional drinking water isolates were obtained by combining samples from 1,500 private wells throughout Wisconsin that had been submitted to the Wisconsin State Laboratory of Hygiene between September and November 1998 for routine coliform testing. The composite samples (composed of 4-10 well samples) were membrane filtered and cultured for Aeromonas as described above. This process yielded an additional $37 \mathrm{~A}$. hydrophila and $17 \mathrm{~A}$. caviae isolates.

PFGE of the stool and groundwater Aeromonas isolates yielded 10-20 well-resolved genomic DNA bands, ranging in size from approximately $10-400 \mathrm{~kb}$ (Figure 2). Six isolates (one stool, five groundwater) were not amenable to $\mathrm{Xba}$ I digestion, resulting in poorly resolved DNA fragments. PFGE patterns indicated extensive genetic diversity. The 65 isolates analyzed by PFGE had 58 distinct patterns. Five patterns grouped two or more identical isolates. Three of those groups included only isolates derived from the same composite water sample, suggesting multiple isolations of the same strain. Analyzing all pairwise comparisons among the 65 isolates, the median similarity was $59 \%$ (range $16 \%$ to $100 \%$, $\mathrm{n}=2,080$ ). Isolates from the same ecologic source also exhibited high genetic diversity. The median similarities of stool and groundwater isolates were $58 \%$ (range $30 \%$ to $76 \%, \mathrm{n}=120$ ) and $60 \%$ (range $25 \%$ to $100 \%, \mathrm{n}=1,176$ ), respectively. Among the 12 isolates from diarrheic stool specimens that were negative for other enteric pathogens, the median similarity was $58 \%$ (range $30 \%-76 \%, n=66)$.

None of the stool isolates was genetically indistinguishable from the groundwater isolates (Figure 2). The two isolates that appeared epidemiologically related, the patient stool isolate (isolate 0209) and the isolate from his private well (isolate 1320 ), were $72 \%$ similar by the Dice coefficient and differed by nine bands, which, following the criteria of Tenover et al. (19), would be generally interpreted as being genetically unrelated. The highest similarity between a stool and water pair of isolates was $88 \%$, between isolates 1251 and 2094, which differed by four bands (Figure 2). However, the stool isolate was from a patient simultaneously positive for Cryptosporidium oocysts, suggesting that the Aeromonas was transient. The second highest similarity was $86 \%$, a four-band difference between isolates 0949 and 1294 (Figure 2). Of the 784 paired comparisons between stool and water isolates, $776(99 \%)$ had similarities $<80 \%$, and the median similarity was $58 \%$ (range $16 \%$ to $88 \%$ ).

\section{Discussion}

The prevalence rate in this study was lower than rates from other large surveillance studies in the United States for Aeromonas in stool. Aeromonas was cultured from 2,848 diarrheic stool specimens submitted to a Los Angeles, California, hospi-

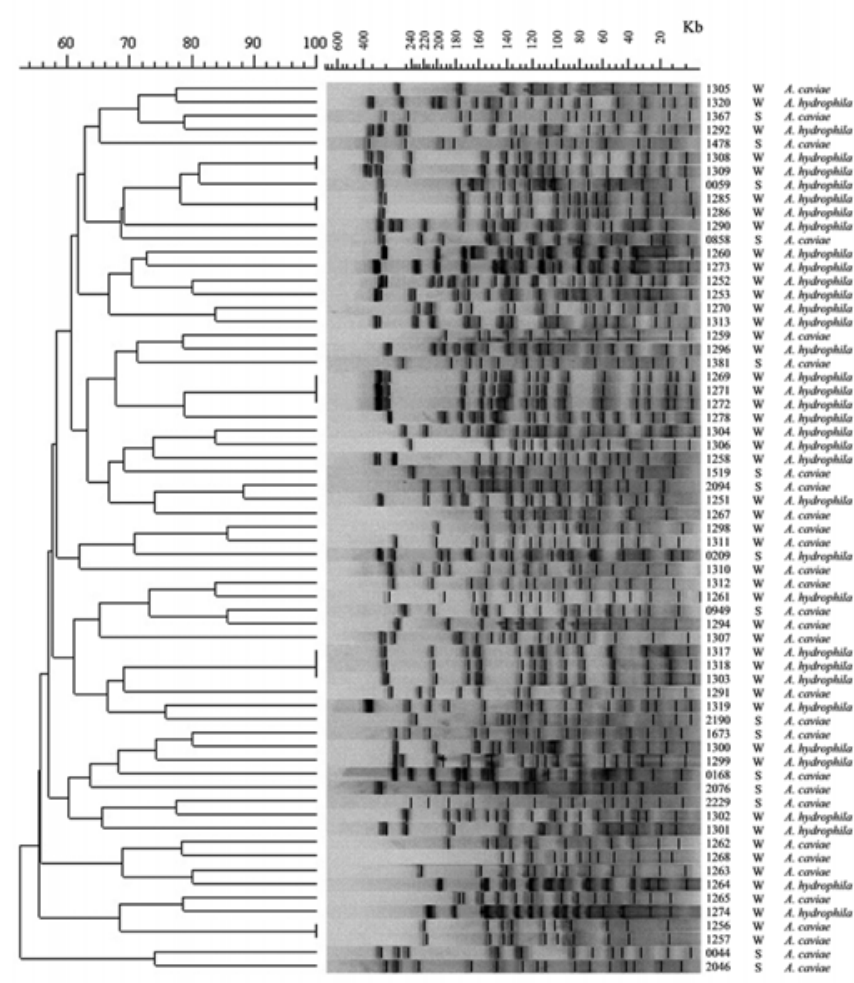

Figure 2. Pulsed-field gel electrophoresis patterns and similarity dendrogram of genomic DNA from Aeromonas hydrophila and $A$. caviae isolates from diarrheic stool (S) and groundwater (W). The number refers to the isolate number. DNA molecular weight scale derived from Staphylococcus aureus NCTC 8325.

tal in the early $1980 \mathrm{~s}$ and $80(2.8 \%)$ were positive (20). Among 1,821 patients with diarrhea visiting a clinic in La Crosse, Wisconsin, during an 18-month period, Agger et al. (21) identified $20(1.1 \%)$ that were positive for $A$. hydrophila. Moyer (18) examined 3,334 diarrheic stool specimens submitted by physicians over a 2-year period to an Iowa public health laboratory and found 238 (7.1\%) positive for either A. caviae, A. hydrophila, or A. sobria. Isolation in the latter study included an alkaline peptone water enrichment step, which may explain the higher prevalence rate. In our study, the specimen prevalence rate was $0.66 \%$, and this rate was likely biased upwards because stool specimens were collected only in the summer and fall months when the incidence of Aeromonas gastrointestinal infections is reportedly highest $(18,21)$. The data, albeit limited, do not suggest that the prevalence of Aeromonas enteric infections is increasing in the United States. Worldwide, the isolation rate of Aeromonas from diarrheic stool has been reported as high as $10.8 \%$ (22) and as low as $0 \%(23)$. In the latter study, recently conducted in Melbourne, Australia, during a 68-week observation period, 795 fecal specimens were collected from city residents with highly credible gastroenteritis. Aeromonas was not detected in any of the fecal specimens, even though $50 \%$ of water samples drawn weekly from the drinking water distribution mains serving the study participants were Aeromonas-positive (23).

The A. hydrophila and A. caviae species designations were equivocal in this study. Except for stool isolate 0858, all iso- 
lates from stool identified by the API-20E system as $A$. caviae were $\beta$-hemolytic, suggesting that they were $A$. hydrophila instead. When the Vitek automated microbe identification system (bioMérieux) was used, all stool and water isolates were identified as the A. hydrophila/caviae group. If the most recent edition of the API analytical profile index were used with the A. caviae profiles derived during the study, the new species designation would be $A$. hydrophila group 1 . Some profiles determined in this study are not listed in the most recent index and, given the ever-changing taxonomy of aeromonads (4), we opted for a consistent one-index approach, reporting the species designations for all stool and water isolates on the basis of the index available at the time of the study.

The high level of genetic diversity observed in our study among clinical and environmental strains of Aeromonas has been corroborated by other nucleic acid-based subtyping methods, such as amplified fragment length polymorphisms (11) and ribotyping (24). Talon et al. (17) subtyped 10 epidemiologically unrelated strains of $A$. hydrophila by PFGE and reported that the median similarity (calculated by using the Pearson correlation coefficient) was $28.4 \%$ (range $9.3 \%$ to $44.3 \%$ ). The variation is not likely due to genetic lability, because the PFGE patterns of Aeromonas reportedly do not become unstable during frozen storage and long-term laboratory culture $(17,25)$. As a control in this study, isolate 1320 was digested and underwent electrophoresis five independent times, and each time yielded the same PFGE pattern. The PFGE patterns also did not correspond to phenospecies. Millership and Want (26) reported a similar finding based on whole-cell protein fingerprinting.

The capacity for human enteropathogenicity among clinical isolates may be derived from a unique set of genes that were acquired or evolved in a common ancestor. Alternatively, enteropathogenicity may have arisen independently among several genotypes. In either scenario, one might expect the subset of Aeromonas strains that are pathogenic to have less genetic variation than the environmental strains. In this study, the level of genetic diversity was similar between environmental and clinical strains, even when the clinical strains were restricted to the subset from stool specimens that were negative for other enteric pathogens. One explanation is that some clinical strains were transient gastrointestinal colonizers, and only a few strains are truly diarrheagenic. This issue will likely remain unresolved until the pathogenicity mechanisms of Aeromonas are better understood.

PFGE is a reproducible, highly discriminatory subtyping method capable of identifying the transmission source of bacterial infections (19). If the Aeromonas-positive patient with the positive well acquired the infection from his drinking water, the molecular fingerprints of the stool and water isolates should at least have been closely related (i.e., $\leq 3$-band difference). Likewise, if drinking water is a frequent source of Aeromonas infections in this study population, one would expect at least a few of the stool and water isolates to be more closely related than a four-band difference. The analysis for this study was weighted towards identifying similar stool and water isolates. The $1.5 \%$ position tolerance that was selected for band calling resulted in matching bands that differed by as much as $17 \mathrm{~kb}$, and the Dice coefficient gives greater weight to matching bands compared to other similarity coefficients.

The study had several limitations, however, that need to be considered when interpreting the data. Only one isolate per stool specimen or water sample was analyzed by PFGE. Multiple strains may have been present in water, and by chance the enteropathogenic strains were not selected for PFGE analysis. Kühn et al. found multiple Aeromonas strains in a single drinking water source, although only one or a few strains were numerically dominant, and these could persist for years $(6,11)$. When duplicate water samples (incubated at $30^{\circ} \mathrm{C}$ and $35^{\circ} \mathrm{C}$ ) both yielded Aeromonas, then PFGE was performed on a colony from each plate. Some of these isolate pairs were indistinguishable by PFGE, and some were unrelated, showing that some composite water samples had at least two different strains. Both strains were included in the genetic similarity analysis. Another study limitation was that if diarrheagenic Aeromonas strains are very rare in groundwater, the sample size might have been insufficient to find those strains, even though the composite water samples tested represented 1,500 wells. The stool and water isolates were collected from the same geographic area and during the same period, which should have increased the odds of finding genetically similar isolates if the two ecologic sources are linked. Finally, the drinking water sample volume for Aeromonas isolation was $100 \mathrm{~mL}$. Since the study was conducted, the EPA has developed and validated Method 1605 for detecting Aeromonas in drinking water, which specifies a minimum sample volume of $1 \mathrm{~L}$ (27). Possibly, if the sample volume had been $1 \mathrm{~L}$, more patient wells would have been Aeromonas positive.

To our knowledge, this is the first study to use PFGE to compare Aeromonas strains from human stool with strains found in groundwater. Other studies have compared the relatedness of strains from drinking water and stool by fatty acid methyl ester profiles (28), ribotyping (29), and randomly amplified polymorphic DNA (30), all highly discriminatory subtyping methods, and found little similarity between clinical and environmental isolates. Aeromonas isolates from stool and drinking water have been linked by biotyping (31) and wholecell protein fingerprinting (25), but the discriminatory power of these methods with Aeromonas is questionable $(28,30)$. Thus, the evidence to date from using highly discriminatory subtyping methods suggests that human enteropathogenic strains are rare in drinking water. In the group of primarily Wisconsin residents in this study, Aeromonas was identified infrequently in diarrheic stool specimens and drinking water from a groundwater source did not appear to be an Aeromonas transmission route.

\section{Acknowledgments}

We thank Phillip Bertz, Sharon Kluender, Jeremy Olstadt, Susan Spencer, and Amy Witte for their technical assistance; Carla Finck for 
providing data management support; Alice Stargardt for assisting with manuscript preparation; and Lynn Ivacic for preparing the graphics.

This work was supported by the Wisconsin Department of Natural Resources.

Dr. Borchardt is a research scientist at Marshfield Medical Research Foundation in Marshfield, Wisconsin. His research interests include waterborne infectious diseases and agricultural zoonoses.

\section{References}

1. Environmental Protection Agency. Announcement of the drinking water Contaminant Candidate List. Federal Register 1998;63:10274-87.

2. Janda JM, Abbott SL. Evolving concepts regarding the genus Aeromonas: an expanding panorama of species, disease presentations, and unanswered questions. Clin Infect Dis 1998;27:332-44.

3. Albert MJ, Ansaruzzaman M, Talukder KA, Chopra AK, Kühn I, Rahman $\mathrm{M}$, et al. Prevalence of enterotoxin genes in Aeromonas spp. isolated from children with diarrhea, healthy controls, and the environment. J Clin Microbiol 2000;38:3785-90.

4. Joseph SW, Carnahan AM. Update on the genus Aeromonas. American Society for Microbiology News 2000;66:218-23.

5. LeChevallier MW, Evans TM, Seidler RJ, Daily OP, Merrell BR, Rollins DM, et al. Aeromonas sobria in chlorinated drinking water supplies. Microbial Ecology 1982;8:325-3.

6. Kühn I, Allestam G, Huys G, Janssen P, Kersters K, Krovacek K, et al. Diversity, persistence, and virulence of Aeromonas strains isolated from drinking water distribution systems in Sweden. Appl Environ Microbiol 1997;63:2708-15.

7. Gavriel AA, Landre JP, Lamb AJ. Incidence of mesophilic Aeromonas within a public drinking water supply in north-east Scotland. J Appl Microbiol 1998;84:383-92.

8. Burke V, Robinson J, Gracey M, Peterson D, Partridge K. Isolation of Aeromonas hydrophila from a metropolitan water supply: seasonal correlation with clinical isolates. Appl Environ Microbiol 1984;48:361-6.

9. Chauret C, Volk C, Creason R, Jarosh J, Robinson J, Warnes C. Detection of Aeromonas hydrophila in a drinking-water distribution system: a field and pilot study. Can J Microbiol 2001;47:782-6.

10. Massa S, Altieri C, D'Angela A. The occurrence of Aeromonas spp. in natural mineral water and well water. Int J Food Microbiol 2001;63:169-73.

11. Kühn I, Huys G, Coopman R, Kersters K, Janssen P. A 4-year study of the diversity and persistence of coliforms and Aeromonas in the water of a Swedish drinking water well. Can J Microbiol 1997;43:9-16.

12. Handfield M, Simard P, Couillard M, Letarte R. Aeromonas hydrophila isolated from food and drinking water: hemagglutination, hemolysis, and cytotoxicity for a human intestinal cell line (HT-29). Appl Environ Microbiol 1996;62:3459-61.

13. Schubert RH. Intestinal cell adhesion and maximum growth temperature of psychrotrophic aeromonads from surface waters. Int J Hyg Environ Health 2000;203:83-5.

14. Janda JM, Abbott SL, Carnahan AM. Aeromonas and Plesiomonas. In: Murray PR, Baron EJ, Pfaller MA, Tenover FC, Yolken RH, editors. Manual of clinical microbiology. 6th ed. Washington: ASM Press; 1995. p. 477-82.

15. American Public Health Association. Standard methods for the examination of water and wastewater. 20th ed. Washington: The Association; 1998. p. 9-111.
16. Maslow JN, Slutsky AM, Arbeit RD. Applications of pulsed-field gel electrophoresis to molecular epidemiology. In: Persing DH, Smith TF, Tenover FC, White TJ, editors. Diagnostic molecular microbiology: principles and applications. Washington: American Society for Microbiology; 1993. p. 563-72.

17. Talon D, Dupont MJ, Lesne J, Thouverez M, Michel-Briand Y. Pulsedfield gel electrophoresis as an epidemiological tool for clonal identification of Aeromonas hydrophila. J Appl Bacteriol 1996;80:277-82.

18. Moyer NP. Clinical significance of Aeromonas species isolated from patients with diarrhea. J Clin Microbiol 1987;25:2044-8.

19. Tenover FC, Arbeit RD, Goering RV, Mickelsen PA, Murray BE, Persing $\mathrm{DH}$, et al. Interpreting chromosomal DNA restriction patterns produced by pulsed-field gel electrophoresis: criteria for bacterial strain typing. J Clin Microbiol 1995;33:2233-9.

20. George WL, Nakata MM, Thompson J, White ML. Aeromonas-related diarrhea in adults. Arch Intern Med 1985;145:2207-11.

21. Agger WA, McCormick JD, Gurwith MJ. Clinical and microbiological features of Aeromonas hydrophila-associated diarrhea. J Clin Microbiol 1985;21:909-13.

22. Burke V, Gracey M, Robinson J, Peck D, Beaman J, Bundell C. The microbiology of childhood gastroenteritis: Aeromonas species and other infective agents. J Infect Dis 1983;148:68-74.

23. Hellard ME, Sinclair MI, Forbes AB, Fairley CK. A randomized, blinded, controlled trial investigating the gastrointestinal health effects of drinking water quality. Environ Health Perspect 2001;109:773-8.

24. Demarta A, Tonolla M, Caminada A, Beretta M, Peduzzi R. Epidemiological relationships between Aeromonas strains isolated from symptomatic children and household environments as determined by ribotyping. Eur J Epidemiol 2000;16:447-53.

25. de la Morena ML, Van R, Singh K, Brian M, Murray ME, Pickering LK. Diarrhea associated with Aeromonas species in children in day care centers. J Infect Dis 1993;168:215-8.

26. Millership SE, Want SV. Characterisation of strains of Aeromonas spp. by phenotype and whole-cell protein fingerprint. J Med Microbiol 1993;39:107-3.

27. Unregulated contaminant monitoring regulation: approval of analytical method for Aeromonas; national primary and secondary drinking water regulations: approval of analytical methods for chemical and microbiological contaminants. Proposed rule. Federal Register 2002;67:10532-49.

28. Havelaar AH, Schets FM, van Silfhout A, Jansen WH, Wieten G, van der Kooij D. Typing of Aeromonas strains from patients with diarrhoea and from drinking water. J Appl Bacteriol 1992;72:435-44.

29. Moyer NP, Luccini GM, Holcomb LA, Hall NH, Altwegg M. Application of ribotyping for differentiating aeromonads isolated from clinical and environmental sources. Appl Environ Microbiol 1992;58:1940-4.

30. Alavandi SV, Ananthan S, Pramod NP. Typing of Aeromonas isolates from children with diarrhoea and water samples by randomly amplified polymorphic DNA polymerase chain reaction and whole cell protein fingerprinting. Indian J Med Res 2001;113:85-97.

31. Holmberg SD, Schell WL, Fanning GR, Wachsmuth IK, Hickman-Brenner FW, Blake PA, et al. Aeromonas intestinal infections in the United States. Ann Intern Med 1986;105:683-9.

Address for correspondence: Mark A. Borchardt, Marshfield Medical Research Foundation, 1000 North Oak Avenue, Marshfield, WI 54449, USA;fax:715-389-3808; e-mail: borcharm@mmrf.mfldclin.edu
All material published in Emerging Infectious Diseases is in the public domain and may be used and reprinted without special permission; proper citation, however, is appreciated.
The opinions expressed by authors contributing to this journal do not necessarily reflect the opinions of the Centers for Disease Control and Prevention or the institutions with which the authors are affiliated. 